\title{
Pecan Scab Fungus Lacks Substrate Specificity for Early Infection Stages
}

\author{
I.E. Yates and K.M.T. Cason \\ U.S. Department of Agriculture-Agricultural Research Service, Russell Research Center, \\ Athens, GA 30613 \\ Darrell Sparks \\ Department of Horticulture, University of Georgia, Athens, GA 30602
}

Additional index words. Carya illinoinensis, Cladosporium caryigenum, abiotic substrates, appressoria, biotic substrates, host-pathogen interface, light, scab resistance, temperature

\begin{abstract}
Leaves and callus of pecan [Carya illinoinensis (Wangenh.) K. Koch], and glass, dialysis membrane, and agar were examined for capacity to support two of the earliest infection stages-conidium (spore) germination and appressorium formation-of Cladosporium caryigenum (Ellis \& Langl.) Gottwald, the fungus causing pecan scab. Light and temperature effects on formation of germ tubes and appressoria were examined for conidia suspended in distilleddeionized water. Conidia formed germ tubes on all substrates and in distilled-deionized water; hence, conidia possessed endogenous materials required for germination and are independent of specific topographic or chemical stimuli. All substrates, except $2 \%$ water agar and water, sustained appressoria development, thus implicating regulation by surface hardness. More appressoria formed on leaf discs than on other substrates. Additionally, conidia formed appressoria with short germ tubes when near a leaf structural feature, such as stomatal guard cells. Thus, the pecan scab fungal isolate used in these experiments appeared to lack substrate specificity for forming germ tubes, but not appressoria, during the prepenetration stages of development. Conidium germination was maximized at about $25{ }^{\circ} \mathrm{C}$ and germination did not respond to light.
\end{abstract}

Pecan is the most economically important horticultural tree crop native to North America. The humid southeastern United States accounts for $75 \%$ of the $\$ 400$ million annual pecan industry in this country (Wood et al., 1990). Scab caused by Cladosporium caryigenum is the most serious fungal disease of pecans grown in humid areas such as the southeastern United States (Latham, 1983). By far, pecan scab causes more damage to pecan than all other diseases combined (Sparks, 1991) and has jeopardized crops since commercial production began (Nolen, 1926). Infected leaves, fruit, and shoots develop characteristic black circular lesions. Damage to susceptible genotypes depends on temperature, leaf wetness, and tissue age (Gottwald, 1985). Severe infections can cause young developing leaves to abscise and elongating shoots to die. Early-season scab disease causes fruit abortion; mid- and lateseason disease suppresses nut quality (Gottwald and Bertrand, 1983). Scab incidence has intensified in the 1990s due to weatherrelated changes resulting in increased humidity (Sparks, 1995).

A major expense for pecans grown in a humid climate is the fungicides and associated scab control operations. Failure to control scab would cause sporadic commercial pecan production (Hadden and Bertrand, personal communication). Control measures need to be developed that reduce expense and minimize fungicide use to decrease detrimental environmental effects. Innovative control measures could be more intelligently designed with a better understanding of the growth requirements and developmental characteristics of the causative organism, C. caryigenum.

Conidium germination requires free moisture (Gottwald, 1985) and is temperature sensitive, with the optimum proposed to be about $25^{\circ} \mathrm{C}$ (Converse, 1956). The light requirement for germination is unknown, and germination and inoculation studies are

Received for publication 2 Feb. 1996. Accepted for publication 24 Apr. 1996 Appreciation is expressed to Donnie Maxey and Joyce Lambert for technical assistance. The cost of publishing this paper was defrayed in part by the payment of page charges. Under postal regulations, this paper therefore must be hereby marked advertisement solely to indicate this fact. usually done under dark conditions (Gottwald, 1985; Latham, 1983; Latham and Rushing, 1988; Yates et al., 1996).

Early events in the infection of the pecan leaf by $C$. caryigenum involve conidium (spore) germination and appressorium formation before leaf cuticle penetration and subcuticular growth (Latham and Rushing, 1988). Appressoria are the first in a series of specialized infection structures that many plant pathogenic fungi form in preparation for invasion of a host (Emmett and Parbery, 1975). Fungal recognition of the appropriate conditions for germ tube and appressorium formation is essential to infection. Response by the fungus may depend on specific topographical and/ or chemical stimuli generated by interacting with the plant (Hoch and Staples, 1991). We have previously documented that $C$. cladosporium conidia formed germ tubes and appressoria on leaves from monocotyledons and dicotyledons and mature and immature resistant and susceptible pecan genotypes (Yates et al., 1996). Germ tube and appressoria frequency did not correlate with host-plant resistance.

The objectives of the current investigation were to determine 1) the optimum temperature for conidium germination, 2) the light requirement, and 3) the dependence of prepenetration interactions between $C$. caryigenum and substrates on physical and/or chemical factors. Germ tube and appressorium formation were analyzed under controlled environmental conditions on biotic (leaf discs and callus) and abiotic (dialysis membrane, glass, and agar) substrates with light and electron microscopy.

\section{Materials and Methods}

Fungal isolate. Cladosporium caryigenum was isolated from infected leaves collected in Spring 1991 from 'Desirable' and in Spring 1993 from 'Wichita' trees growing at the Univ. of Georgia Horticulture Farm, Watkinsville. Conidia from sporulating lesions were inoculated on potato dextrose agar (PDA) (Difco, Detroit), and cultures were maintained at $24^{\circ} \mathrm{C}$ with constant illumination at $85 \mu \mathrm{mol} \cdot \mathrm{m}^{-2} \cdot \mathrm{s}^{-1}$ by cool-white fluorescent $40-\mathrm{W}$ bulbs (General 
Electric, Nela Park, Cleveland). Axenic cultures were obtained by successive selection and maintained by monthly transfer to fresh PDA agar.

Source of substrates for in vitro analyses. Germ tube formation and appressorium development by conidia of $C$. caryigenum isolated from 'Desirable' pecan were evaluated in sterile distilleddeionized water and on five other substrates: pecan leaves, pecan callus, glass slides, dialysis membrane, and agar. Scab-free $<14-$ day-old leaves were collected from trees of 'Wichita', a scabsusceptible cultivar. The second leaflets from the base of the leaf were taken from each of four 3-year-old trees grown under greenhouse conditions. Plants were grown in containers $(60 \mathrm{~cm}$ high with a $30-\mathrm{cm}$ top diameter) filled with a commercial soil mix (Fafard Mix no. 3; Conrad Fafard, Agawam, Mass.). Plants were pruned monthly from March until November to ensure a continuous supply of young scab susceptible leaves. Insect pests were monitored weekly and controlled by an occasional spray of $1 \%$ Ivory liquid detergent. Leaf tissue used for analysis was never subjected to spraying, as only young leaves < 14 days after budbreak were collected for experiments. Discs (10 $\mathrm{mm}$ in diameter) were cut from the leaflets with a cork bore and used immediately as substrate for conidium germination as described below.

Pecan embryonic callus was originated from immature zygotic embryos of 'Wichita' (Yates and Reilly, 1990). Cultures were maintained by bimonthly transfers to fresh basal medium (Tulecke and McGranahan, 1985). Compact callus tissue with a white, moist appearance was dissected into pieces of about $10 \mathrm{~mm}$ in diameter as substrate for conidium germination.

Cellulose dialysis membrane (molecular weight cutoff 12 14,000; Spectrum Medical Industries, Los Angeles) was cut into 10-mm-diameter discs. Membrane discs were autoclaved for 20 min in deionized-distilled water and used immediately. Microscope cover glasses (12 mm in diameter; Ted Pella, Redding,



Fig. 1. Germination of Cladosporium caryigenum conidia on biotic and abiotic substrates. Substrates with common letter are not statistically different for germination frequency, $P \leq 0.05$.
Calif.) were used as the glass substrate. Slides were washed before use in soapy water, rinsed at least five times in deionized-distilled water, rinsed in $95 \%$ ethanol, then rinsed five times in deionizeddistilled water. Agar (purified; Difco) was solubilized in deionized-distilled water at $2 \%$, autoclaved for $20 \mathrm{~min}$, solidified at a thickness of $4 \mathrm{~mm}$ in petri dishes, and cut with a sterile cork bore into $10-\mathrm{mm}$ discs.

Influence of the substrate on germ tube and appressorium development. Agar discs were placed onto each of 12 sections of a sterile serological ring slide (Fisher Scientific, Atlanta). Leaf discs were mounted on agar that contained $1 \mathrm{~mm} \mathrm{Ca}\left(\mathrm{NO}_{3}\right)_{2}, 1 \mathrm{~mm}$ benzimidazole, and $1.2 \%$ agar (BIZ agar) (S. Somerville, personal communication) to retard senescence and maintain hydration of the leaf tissue. The substrates of callus, glass slides, and dialysis membrane were mounted also on agar, but without additives, to ensure uniform humidity for conidium germination on all surface types. In another series of experiments, conidia were assayed for germ tube and appressorium formation in sterile distilled-deionized water contained in test tubes.

Conidia were applied to each substrate surface with a camel hair paint brush directly from a culture of $C$. caryigenum. Each substrate was replicated three or four times in a randomized completeblock design. Each ring slide represented a block (Redlin and Stack, 1990). Slides were placed in sterile glass petri dishes inside a desiccator maintained at $97 \%$ relative humidity with $\mathrm{CuSO}_{4}$ (Young, 1967) and incubated $24 \mathrm{~h}$ at $24^{\circ} \mathrm{C}$ using a 12-h photoperiod at $40 \mu \mathrm{mol} \cdot \mathrm{m}^{-2} \cdot \mathrm{s}^{-1}$ by cool-white fluorescent $40-\mathrm{W}$ bulbs. Conidium germination and appressorium formation were analyzed $24 \mathrm{~h}$ after inoculation.

Distilled-deionized water was used as the substrate to study the light and temperature requirements for germination by conidia of C. caryigenum isolated from 'Wichita' pecan. The surface of a

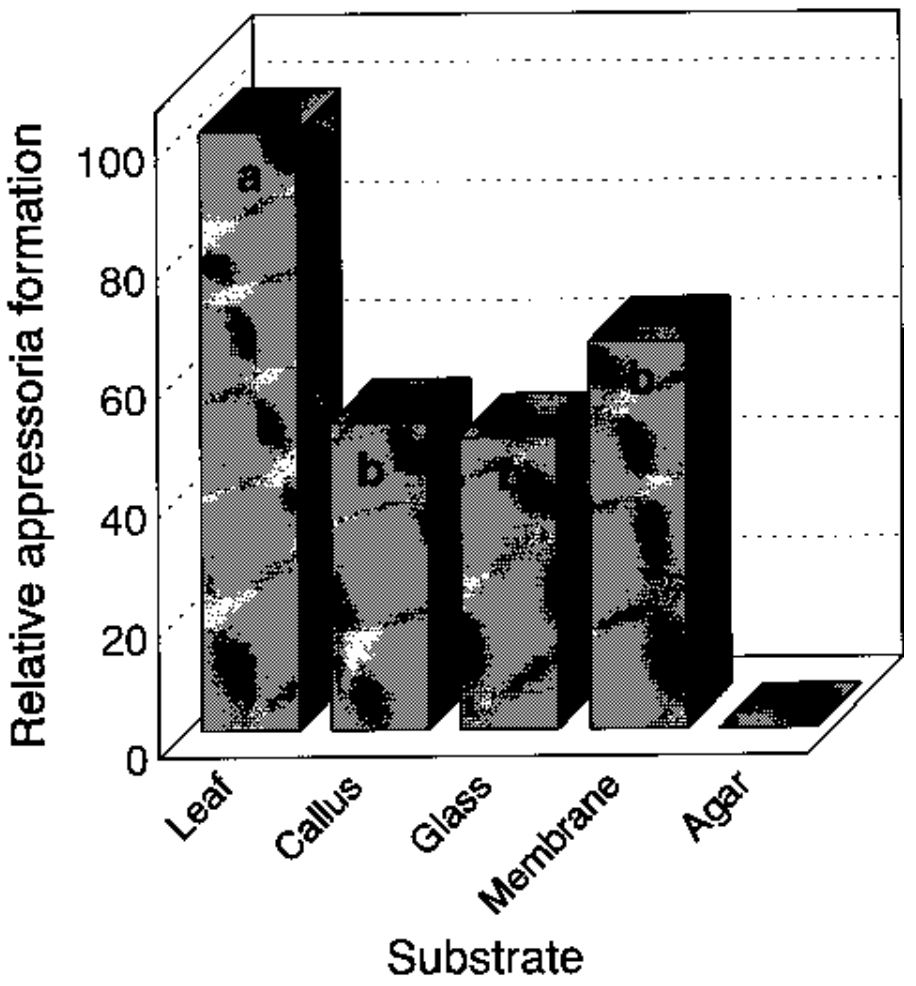

Fig. 2. Appressoria formation of Cladosporium caryigenum conidia on biotic and abiotic substrates. Substrates with common letter are not statistically different for appressorium frequency, $P \leq 0.05$. 
culture growing on PDA was washed with $1 \mathrm{~mL}$ of sterile distilleddeionized water and filtered through nylon filters (mesh opening $10 \mu \mathrm{m} ;$ Spectra/Mesh, Spectrum, Houston). Conidia in the filtrate were diluted to about $10^{4} / \mathrm{mL}$ and $100 \mu \mathrm{L}$ of conidial suspension added to $12 \times 75-\mathrm{mm}$ borosilicate glass test tubes that had been previously rinsed at least three times with distilled-deionized water. At least 10 test tubes were analyzed at each temperature. Tubes were incubated overnight in controlled environmental chambers at 14 to $32^{\circ} \mathrm{C}$ spanning $2^{\circ}$ or $4^{\circ}$ intervals within this range. To analyze the influence of light, test tubes were incubated at $25^{\circ} \mathrm{C}$. One set of test tubes was covered with aluminum foil to exclude light. After overnight incubation, specimens were fixed in $2 \%$ glutaraldehyde.

Conidia were judged as germinated when either 1) germ tubes grew to a length equal to or exceeding the width of the conidium or 2) appressoria formed without an obvious germ tube. Appressoria were considered to have formed when the hyphae tip was swollen with a single or double lobe and delimited with a septum. Relative germination and appressorium formation were calculated by setting the highest percentage within a replication at 100 . Statistical comparisons between light versus dark incubation and among substrates for supporting germ tube development and appressorium formation were by analysis of variance with means separated by LSD (Gomez and Gomez, 1984). The distance of 30 conidia to stomates and length of germ tubes were measured on 10 different leaf discs with a light microscope (Leitz Dialux 22 EB; LEICA, Wetzlar, Germany) equipped with a micrometer disc. Measurement criteria were that the conidium had a germ tube, not a directly formed appressorium and that the conidium was not touching a guard cell. Stomates were an obvious leaf surface structure that could be easily distinguished as a topographic feature. Data were analyzed by regression analysis (Gomez and Gomez, 1984). Temperature effect on conidium germination were also delineated by regression.

Microscopy. Tissue samples examined by light microscopy (LM) were fixed in formalin-propionic acid-50\% ethanol (1:1:20, by volume), stained overnight in $95 \%$ ethanol-glacial acetic acid (1:1) with $0.0175 \mathrm{mg} \cdot \mathrm{mL}^{-1}$ acid fuchsin, destained for 1 to 3 days in $4.5 \mathrm{~g} \cdot \mathrm{mL}^{-1}$ chloral hydrate, and stored in lactophenol (McBryde, 1936). Specimens were examined with a LM (Leitz Dialux 22 EB; LEICA). Leaf discs and compact callus for observations by scanning electron microscopy (SEM) were inoculated with conidia of C. caryigenum, fixed overnight at $4{ }^{\circ} \mathrm{C}$ in $2 \%$ glutaraldehyde in $0.085 \mathrm{M}$ cacodylate buffer $(\mathrm{pH} 7.2)$, dehydrated in an ethanol series, and critical-point dried. Infected tissue was mounted on stubs and coated with gold-palladium. Samples were examined at $15 \mathrm{kV}$ with a SEM (model 505; Division of North American Philips Corp., Mahwah, N.J.).

\section{Results}

Substrate influence on germination and appressorium formation. Germination of $C$. caryigenum conidia was not different on biotic substrates of leaf discs and callus from that on abiotic substrates of dialysis membrane, glass, or agar (Fig. 1). Likewise, conidia produced germ tubes in sterile distilled-deionized water. In contrast to germination, appressorium frequency depended on substrate, with formation substantially higher on leaf discs than any other substrate (Fig. 2). Appressoria developed on callus, dialysis membrane, and glass, but never on agar or in water. The possibility that an inhibitor was present in the agar would be remote in that the experimental design included mounting the substrates of callus, glass slides, and dialysis membrane on agar.
Appressoria occurred with equal frequency on the biotic substrate, callus, as on the abiotic substrates of glass and dialysis membrane.

Substrate influence on developmental patterns of germ tubes and appressoria. Number and length of germ tubes formed by a single conidium differed according to the substrate (Fig. 3). Conidia on leaf discs usually formed a single germ tube (Fig. 3A) and only occasionally formed two germ tubes. Conidia usually

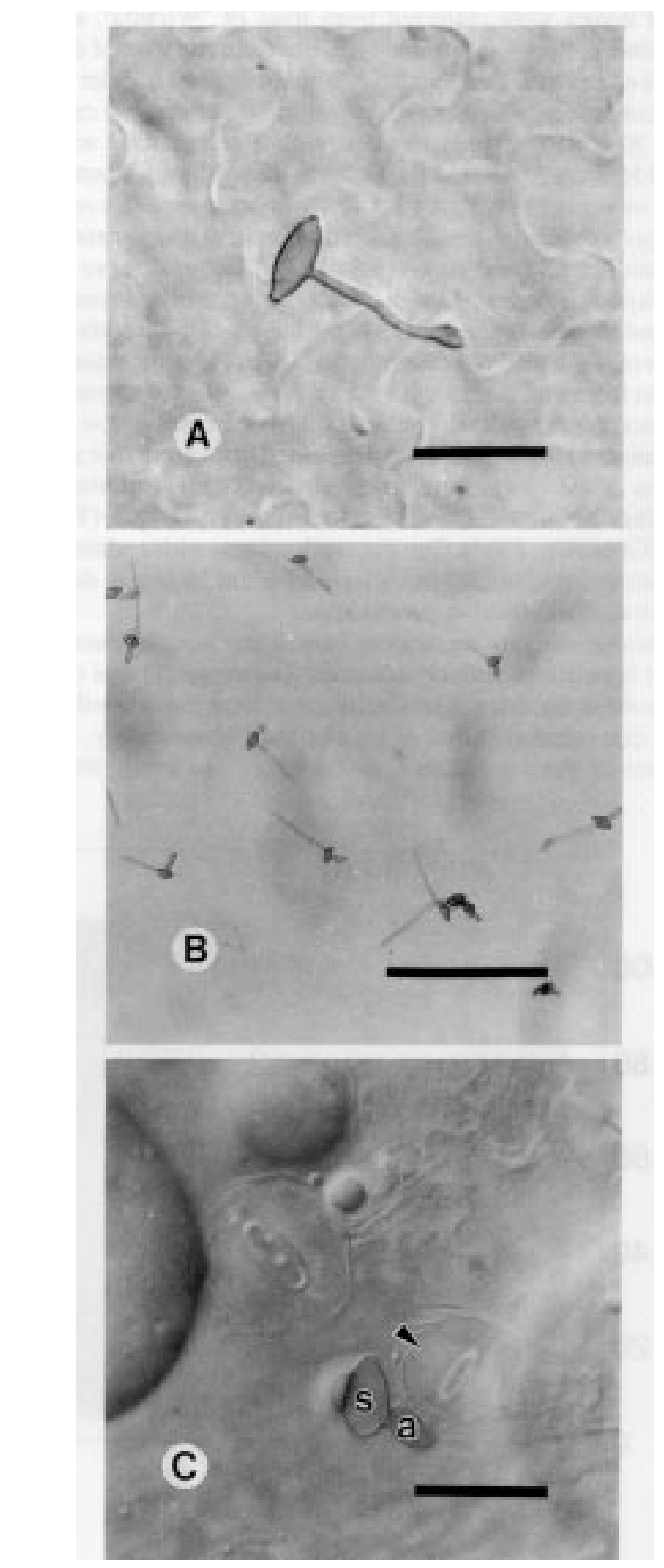

Fig. 3. Light micrographs of variable germ tube formation. A germinating conidium usually formed one tube on pecan leaf pieces (A), two tubes on either glass or dialysis membrane (B), and no apparent germ tube at leaf sites near a topographic feature, such as a stomatal guard cell (indicated by point) $(\mathbf{C})$. Abbreviations: $=$ conidium or spore, $\mathrm{a}=$ appressorium. Bars $=25 \mu \mathrm{m}(\mathbf{A}$ and $\mathbf{C}), 100 \mu \mathrm{m}(\mathbf{B})$. 


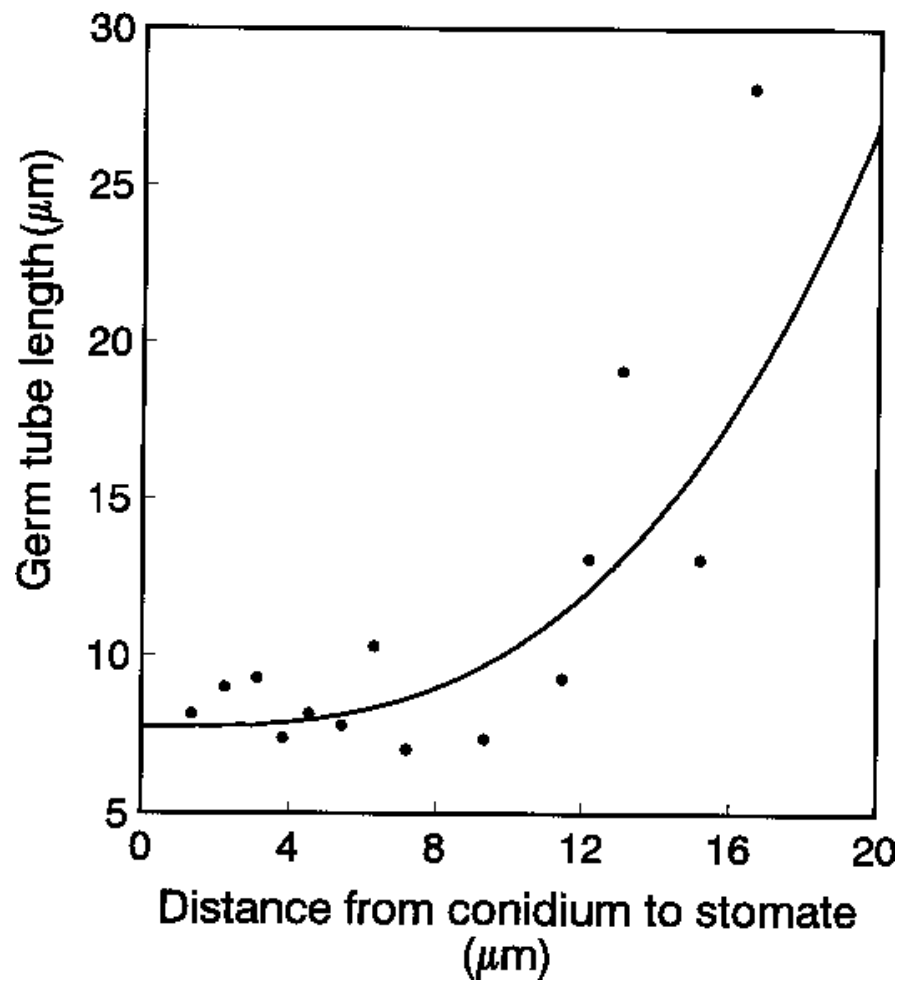

Fig. 4. The response of germ tube length $(\mathrm{x})$ to conidium proximity $(\mu \mathrm{m})$ to stomate (y) is described by $\mathrm{Y}=7.7497+0.0024 \mathrm{X}^{3}, r^{2}=0.77$. Regression coefficient is significantly different from zero, $P \leq 0.05$.

formed two germ tubes on either dialysis membrane or glass (Fig. 3B).

Conidia formed long germ tubes (Fig. 3 A and B) on artificial substrates of callus, dialysis membrane, glass, and agar, and on leaf sites distant from a topographic feature, such as a stomatal guard cell. Often, no apparent germ tube formed on pecan leaves when conidia were located near the base of a trichome, the elevated area of a vein, or a guard cell (Fig. 3C). Visual observations that proximity of a leaf structural feature influenced germ tube length were confirmed by measuring germ tube length and conidium distance to a stomate. A cubic relationship existed between germ tube length and distance of the conidium from the stomate (Fig. 4). Conidia separated from stomates by $\leq 5 \mu \mathrm{m}$ produced germ tubes that grew straight toward the stomate. However, long germ tubes not encountering a leaf structural feature to stimulate appressoria formation were often curved (Fig. 3A).

Substrate type and, for leaf discs, conidium location on the leaf influenced appressorium morphology (Fig. 5). Conidia next to a leaf surface structural component, such as a guard cell, often formed appressoria with single ovate or globular lobes without visual evidence of intervening germ tubes (Fig. 5A). In contrast, conidia formed distinctive germ tubes with double-lobed appressoria when at a leaf site distant from a topographical alteration in the leaf surface (Fig. 5B). Visual evidence of a secretory product was often apparent at sites surrounding appressoria (Fig. $5 \mathrm{~A}$ and B), regardless of appressorium shape. Appressoria formed on callus, dialysis membrane, and glass were all single lobed. On pecan callus, appressoria appeared as single, elongated lobes at the tips of long germ tubes (Fig. 5C).

Light and temperature effects on germination. Conidium germination was not influenced by light. Relative germination was 83 and 80 for light and dark treatments, respectively. Germination varied significantly with temperature and was optimum at about 25
${ }^{\circ} \mathrm{C}$ (Fig. 6). The optimum range was narrow and germination rapidly decreased from the optimum temperature.

\section{Discussion}

Germination of conidia (spores) has been used as a bioassay to analyze pecan leaf extracts regulating development of pecan scab disease (Hedin et al., 1979; Wood et al., 1988). Differential germination, depending on the extracted chemical constituent, has been proposed as evidence that such constituents may be responsible for different scab susceptibilities exhibited by pecan cultivars. Conidium germination has several characteristics required of a practical bioassay with regard to ease of execution, obvious
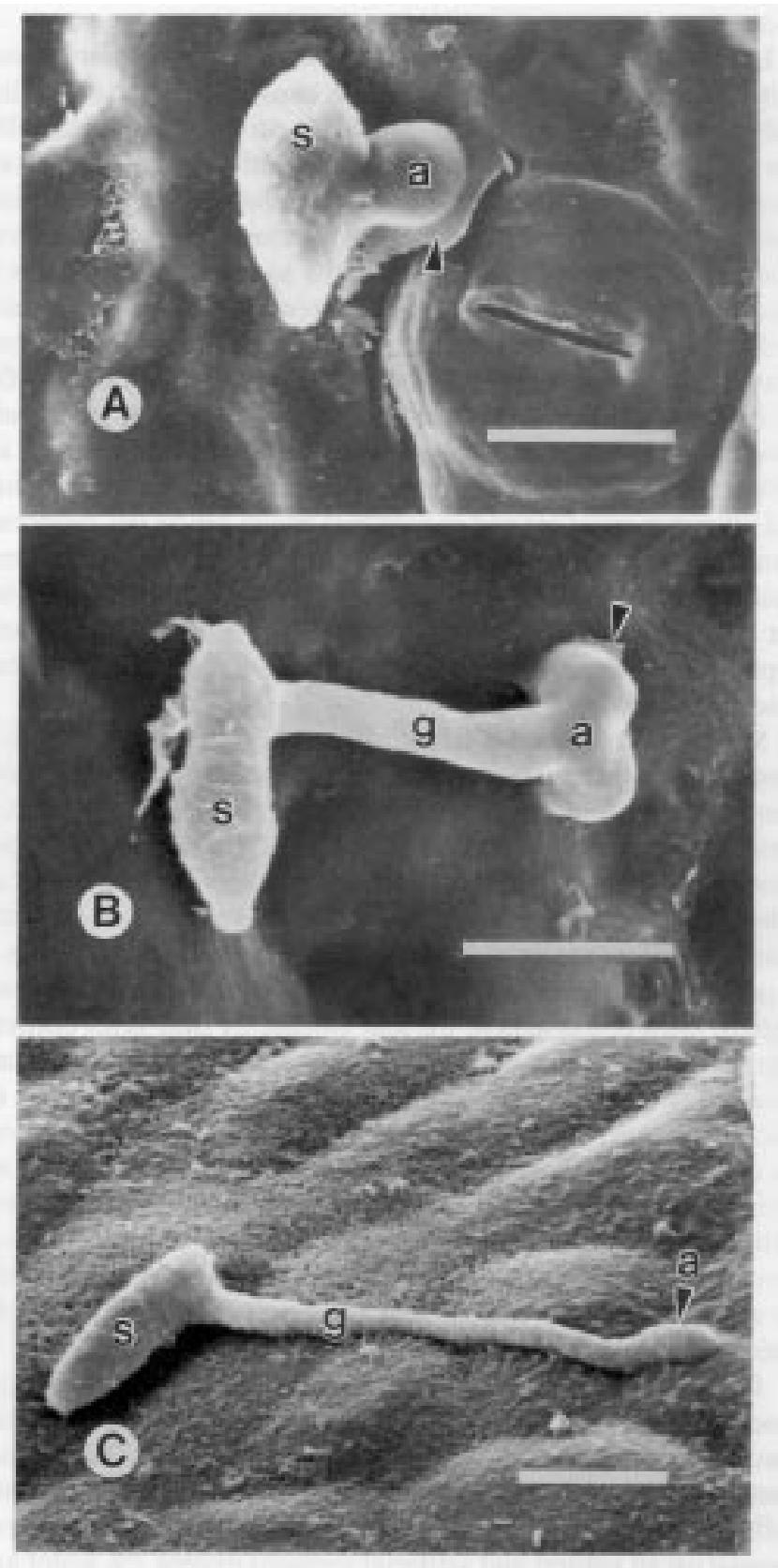

Fig. 5. Scanning electron micrographs of variable appressorium morphology. Appressoria formed on leaves as single lobes at sites near a topographic feature such as a guard cell (A), but as double lobes at sites distant to a topographical feature (B). Points indicate apparent secretion around appressorium periphery (A and B). Appressoria formed as single lobes on pecan callus $(\mathbf{C})$. Abbreviations: $\mathrm{s}=$ conidium or spore, $\mathrm{g}=$ germ tube, $\mathrm{a}=$ appressorium. Bars $=10 \mu \mathrm{m}$. 
endpoint, rapid results, and low cost to test chemical activity (Yates, 1984). Although germination can be used as a bioassay to examine the influence of isolated leaf fractions on growth and development, results in this study and a previous investigation (Yates et al., 1996) suggest a more critical diagnostic marker is necessary for judging scab susceptibility. Germ tubes occur with equal frequency on glass and the natural substrate of the leaf and other abiotic and biotic substrates. The ability of $C$. caryigenum conidia to germinate on glass slides and in distilled-deionized water indicates endogenous materials are present to support germ tube growth. Furthermore, our previous work demonstrated that germ tubes formed with even greater frequency on leaves of a resistant than a susceptible pecan host. Thus, we propose that conidium germination is a nonspecific developmental process for C. caryigenum.

Likewise, appressoria development would appear to lack specificity in that this infection structure readily formed on callus, dialysis membrane, and glass, but never on agar. The possibility that an inhibitor present in the agar would retard appressoria development is negligible in that the other substrates, callus, glass slides, and dialysis membrane, were mounted also on agar. Even though diffusion of molecules from the agar though the callus or glass slides is unlikely, small-molecular-weight compounds would be distributed through the membrane to reach the spores. Furthermore, we have not only previously documented a lack of specificity by susceptible and resistant pecan genotypes for germ tube development, but also for appressorium formation (Yates et al., 1996). Leaves from monocotyledons and dicotyledons and mature and immature resistant and susceptible pecan genotypes supported formation of germ tubes and appressoria. Germ tube and appressoria frequency varied among genotypes and with leaf maturity, but was not correlated with host plant resistance. Subcuticular hyphae development was the fungal stage that was specific for a susceptible host.

Materials endogenous to conidia support germ tube development, and neither surface topography nor the substrate composition regulated conidium germination (Fig. 1) under conditions of these experiments. Wood et al. (1988) reached a conflicting conclusion that germination partially depended on leaf surface substances and proposed that leaf substances affect scab susceptibility. A difference in our investigations and their study was in experimental protocol. Wood et al. (1988) separated water and organic solvent extracts of the leaf surface by thin-layer chromatography. Fractions were suspended in a thin film of water on a glass slide with $C$. caryigenum conidia. The influence of the fractions ranged from inhibitory to stimulating, with some having no effect. In our study, germination was neither inhibited nor stimulated in comparisons of the leaf surface natural substrate to artificial substrates, whether of a biotic (callus) or an abiotic (glass, membrane, agar) nature. Effects of such inhibitory chemicals may be suppressed by the natural leaf biosphere involving a complex interaction of attributes.

Development of appressoria by $C$. caryigenum may be governed by a combination of factors, including chemicals, surface hardness, and topography. The influence of these factors is suggested by differential appressoria frequency on the leaf surface to callus, dialysis membrane, glass, and water agar. Appressoria formed on all natural and artificial surfaces except $2 \%$ water agar and in distilled-deionized water, therefore suggesting that surface hardness may augment appressorium development. Higher frequency of appressorium formation on leaf surfaces may suggest chemical/topographic influences. Other fungi have been reported to form appressoria on artificial substrates (Gold and Mendgen,

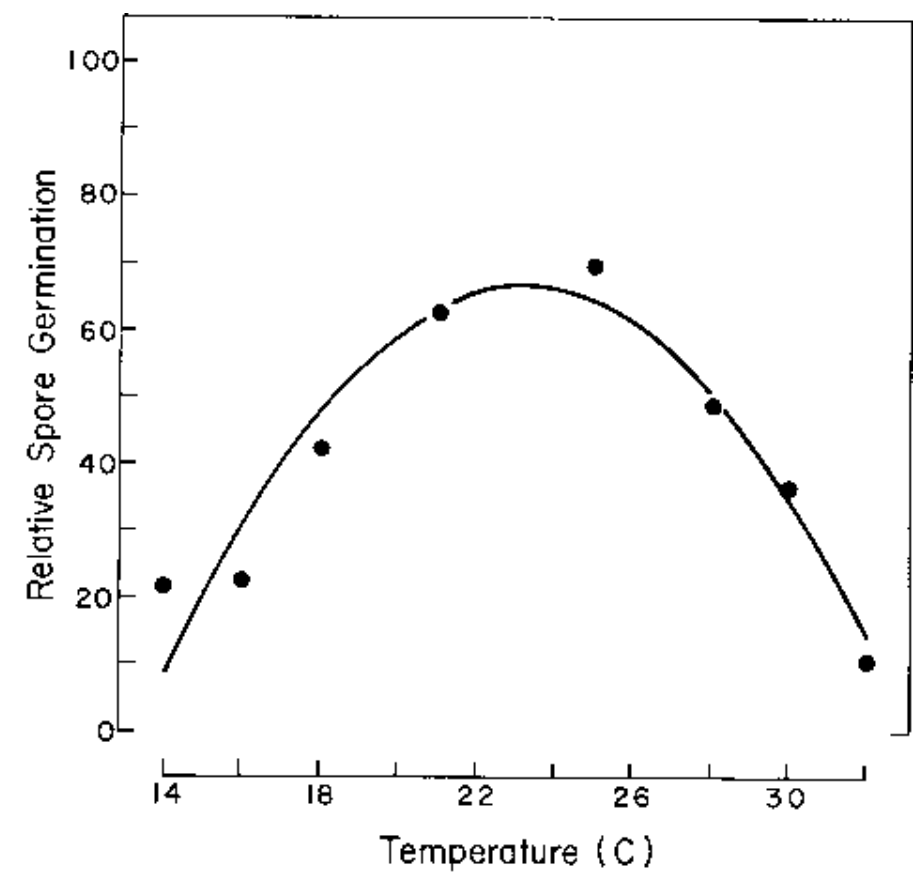

Fig. 6. Germination of conidia as a function of temperature. The relationship is described by $\mathrm{Y}=-318.5+29.2 \mathrm{X}-0.66 \mathrm{X}^{2}+12.7 \sqrt{\mathrm{X}}, r^{2}=0.68$. Regression coefficients are significantly different from zero, $P \leq 0.05$.

1991). Surface hardness and water availability were interpreted as influencing infection structures developed from rust conidia on artificial membranes (Freytag et al., 1988; Hansen and Patton, 1975; Mims and Richardson, 1989) and glass (Freytag et al., 1988). A positive response to contact stimuli in appressorium formation has been amply documented (Wynn and Staples, 1981). A sharp change in substrate elevation of $0.5 \mu \mathrm{m}$ was effective for prompting Uromyces appendiculatus to form appressoria (Hoch et al., 1987).

The inability of a conidium to form the infection structure necessary for leaf penetration, an appressorium, in water may have special significance in scab control. During any rain period, or, more specifically, as long as the leaf is wet, the conidium will germinate but infection would not be expected to occur due to lack of appressorium formation. Thus, in the rain-triggered scab control program (Sparks, 1995), the possibility exists that fungicide application should be based on time from cessation of rain, rather than on time from onset of rain.

The lack of a light effect gives credence to germination studies conducted under dark conditions (Gottwald, 1985; Latham, 1983; Latham and Rushin, 1988; Yates et al., 1996). The optimum temperature for conidium germination, $25^{\circ} \mathrm{C}$, confirms the optimum proposed by Converse (1956). Furthermore, the optimum for germination is the same as that for lesion development (Gottwald, 1985). The abrupt decrease in germination on either side of the optimum also occurs for infection. Low conidium germination at extreme temperatures suggest that temperature should be considered in a scab control program as has been proposed (Sparks, 1995).

In summary, evidence is presented that $C$. caryigenum conidia germinate on pecan foliage independent of unique topographical or chemical requirements. Appressorium formation exhibited more substrate selectivity, having a higher frequency on the pecan leaf surface than other substrates, and with none formed on agar or in water. We propose that the only requirement for conidium germination is appropriate moisture and temperature conditions. We 
have determined that conidium germination is independent of light but dependent on temperature. The optimum temperature of $25^{\circ} \mathrm{C}$ for conidium germination coincides with the previously reported optimum temperature for lesion development. Furthermore, mechanisms responsible for scab resistance in certain pecan and scab genotype combinations may not be operative during germ tube or appressorium development. Even though the impact of chemical promoters and/or inhibitors in the determination of scab resistance remains to be determined, we postulate that such factors exhibit little or no influence on either germ tube or appressorium formation and that the primary mechanism of resistance are found at other levels of the host-pathogen interaction.

\section{Literature Cited}

Converse, R.H. 1956. The production and germination of conidia of Cladosporium effusum (Wint.) Demaree in the laboratory. Phytopathology 46:9 (Abstr.).

Emmett, R.W. and D.G. Parbery. 1975. Appressoria. Annu. Rev. Phytopathol. 13:147-167.

Freytag, S., L. Bruscaglioni, R.E. Gold, and K. Mendgen. 1988. Basidiospores of rust fungi (Uromyces species) differentiate infection structures in vitro. Expt. Mycol. 12:275-283.

Gold, R.E. and K. Mendgen. 1991. Rust basidiospore germlings and disease initiation, p. 67-99. In: G.T. Cole and H.C. Hoch (eds.). The fungal spore and disease initiation in plants and animals. Plenum Press, New York.

Gomez, K.A. and A.A. Gomez. 1984. Statistical procedures for agricultural research. Wiley, New York.

Gottwald, T.R. 1985. Influence of temperature, leaf wetness period, leaf age, and spore concentration on infection of pecan leaves by conidia of Cladosporium caryigenum. Phytopathology 75:190-194.

Gottwald, T.R. and P.F. Bertrand. 1983. Effect of time of inoculation with Cladosporium caryigenum on pecan scab development and nut quality. Ecol. Epidemiol. 73:714-718.

Hansen, E.M. and R.F. Patton. 1975. Types of germination and differentiation of vesicles by basidiospores of Cronartium ribicola. Phytopathology 65:1061-1071.

Hedin, P.A., V.E. Langhans, and C.H. Graves, Jr. 1979. Identification of juglone in pecan as a possible factor of resistance to Fusicladium effusum. J. Agr. Food Chem. 27:92-94.

Hoch, H.C. and R.C. Staples. 1991. Signaling for infection structure formation in fungi, p. 25-46. In: G.T. Cole and H.C. Hoch (eds.). The fungal spore and disease initiation in plants and animals. Plenum Press, New York.
Hoch, H.C., R.C. Staples, B. Whitehead, J. Comeau, and E.D. Wolf. 1987. Signaling for growth orientation and cell differentiation by surface topography in Uromyces. Science 235:1659-1662.

Latham, A.J. 1983. Control of Cladosporium caryigenum on pecan leaves and nut shucks with propiconazole (CGA-64250). Plant Dis. 57:11361139

Latham, A.J. and A.E. Rushing. 1988. Development of Cladosporium caryigenum in pecan leaves. Phytopathology 78:1104-1108.

McBryde, M.C. 1936. A method of demonstrating rust hyphae and haustoria in unsectioned leaf tissue. Amer. J. Bot. 23:686-689.

Mims, C.W. and E.A. Richardson. 1989. Ultrastructure of appressorium development by basidiospore germlings of the rust fungus Gymnosporangium juniperi-virginianae. Protoplasma 148:111-119.

Nolen, R.E. 1926. Pecan scab. Univ. Florida Agr. Expt. Sta. Bul. 181.

Redlin, S.C. and R.W. Stack. 1990. An in vitro technique to evaluate infection of Fraxinus pennsylvanica by Gnomoniella fraxini, p. 137145. In: W. Merrill and M. Ostry (eds.). Recent research on foliage diseases. U.S. For. Serv. Gen. Tech. Rpt. WO-56.

Sparks, D. 1991. Cultural practices, p. 22-33. In: B.W. Wood and J.A. Payne (eds). Pecan husbandry: Challenges and opportunities. First Natl. Pecan Workshop Proceedings, U.S. Dept. Agr., Agr. Res. Serv., ARS96.

Sparks, D. 1995. A climatic approach to pecan scab control. HortTechnology 5:225-230.

Tulecke, W. and G. McGranahan. 1985. Somatic embryogenesis and plant regeneration from cotyledons of walnut, Juglans regia L. Plant Sci. 40:57-63.

Wood, B.W., T.R. Gottwald, and C.C. Reilly. 1988. Pecan phylloplane chemicals influence germination of pecan scab conidia. J. Amer. Soc. Hort. Sci. 113:616-619.

Wood, B.W., J.A. Payne, and L.J. Grauke. 1990. The rise of the U.S. pecan industry. HortScience 25:594, 721-723.

Wynn, W.K. and R.C. Staples. 1981. Tropisms of fungi in host recognition, p. 45-69. In: R.C. Staples and G.H. Toenniessen (eds.). Plant disease control-Resistance and susceptibility. Wiley-Interscience, New York.

Yates, I.E. 1984. Bioassay systems and their use in the diagnosis of mycotoxicoses, p. 333-378. In: J.L. Richard and J.R. Thurston (eds.). Diagnosis of mycotoxicoses. Martinus Nijhoff Publishers, Boston.

Yates, I.E. and C.C. Reilly. 1990. Somatic embryogenesis and plant development in eight cultivars of pecan. HortScience 25:573-576.

Yates, I. E., D. Maxey, S. Lee, D. Sparks, and C.C. Reilly. 1996. Development of the pecan scab fungus on susceptible and resistant host and nonhost leaves. J. Amer. Soc. Hort. Sci. 121:350-357.

Young, J.F. 1967. Humidity control in the laboratory using salt solutions-A review. J. Applied Chem. 17:241-245. 